\title{
Beamsteering of 8x1 Circular Patch Phased Array Antenna at L Band for Airborne Applications
}

\author{
U.Srinivasa Rao
}

\begin{abstract}
This paper presents modelling and simulation of a Microstrip Line Quarter Wave Transformer-fed 8x1 Circular Patch Antenna is presented. The maximum size of proposed array antenna is $900 \mathrm{~mm} \times 300 \mathrm{~mm} \times 24 \mathrm{~mm}$. The substrate material used for this antenna has thickness of $1.588 \mathrm{~mm}$ and relative permittivity (\&r) is $\mathbf{2 . 2}$. The design frequency of the antenna is $2 \mathrm{GHz}$ and VSWR $\leq 2$.The proposed antenna is modelled and simulated using ANSOFT HFSS 15.0 version. The gain of this array antenna is $14.11 \mathrm{~dB}$ and return loss of $-13.5 \mathrm{~dB}$. The phased array antenna is steered for 100,200 and 300 with the beam width of 13.6 and bandwidth of $57 \mathrm{MHz}$. These type of antennas are very useful for airborne applications.
\end{abstract}

Index Terms - Quarter wave Transformer, Circular Patch Antenna, Beamsteering, Gain, Return loss, Beamwidth.

\section{INTRODUCTION}

Microstrip patch antennas are popular, because they have some advantages due to their conformal and simple planar structure. They allow all the advantages of printed-circuit technology. A vast number of papers are available in the literature, investigating various aspects of microstrip antennas. Development of microstrip antennas was initiated in 1981, where a space-borne, light-weight, and low-profile planar array was needed for a satellite communication system. Since then, the development of the microstrip antenna has been expanded into three major program areas: mobile satellite (MSAT) communication, earth remote sensing, and deep-space exploration.

The term "Microstrip" comes because the thickness of this metallic strip is in micro-meter range. Microstrip patch antennas are popular, because they have some advantages due to their conformal and simple planar structure. They allow all the advantages of printed-circuit technology. Next we describe the procedure for increasing the antenna bandwidth. Finally, the simulated results are described, and it can be used for communication and other applications.

\section{Design AND ANALYSIS OF 8X1 CIRCUlar PATCH ARRAY ANTENNA}

The array factor for $\mathrm{N}$ elements in general is

$$
\mathrm{AF}=\left[\frac{\sin \left(\frac{N}{2} \psi\right)}{\sin \left(\frac{1}{2} \psi\right)}\right]
$$

Where

U.Srinivasa Rao,Associate Professor and Head, Department of ECE in Vignan's Lara institute of Technology and Science, Vadlamudi, Andhra Pradesh, India. $\psi=k d \cos \theta+\left.\beta\right|_{\theta=\theta_{0}}=k d \cos \theta_{0}+\beta=0 \Rightarrow \beta=-k d \cos \theta_{0}$

The direction of the major radiation from an array can be controlled by changing the phase excitation between the elements. It is then logical to assume that the maximum radiation can be oriented in any direction to form a scanning array.

To accomplish this, the phase excitation $B$ between the elements must be adjusted. Thus by controlling the progressive phase difference between the elements, the maximum radiation can be squinted in any desired direction to form a scanning array. This is the basic principle of electronic scanning phased array operation. Since in phased array technology the scanning must be continuous, the system should be capable of continuously varying the progressive phase between the elements.

The elements are placed such that the spacing between them is $\lambda / 2$. All the elements are fed with the same amplitude and difference in phase. The phased array antenna is steered for $10^{0}, 20^{\circ}$ and $30^{\circ}$ by changing the progressive phase between the elements .

The structure of modeled and simulated $8 \mathrm{X} 1$ circular patch phased array antenna is shown in Fig.1.

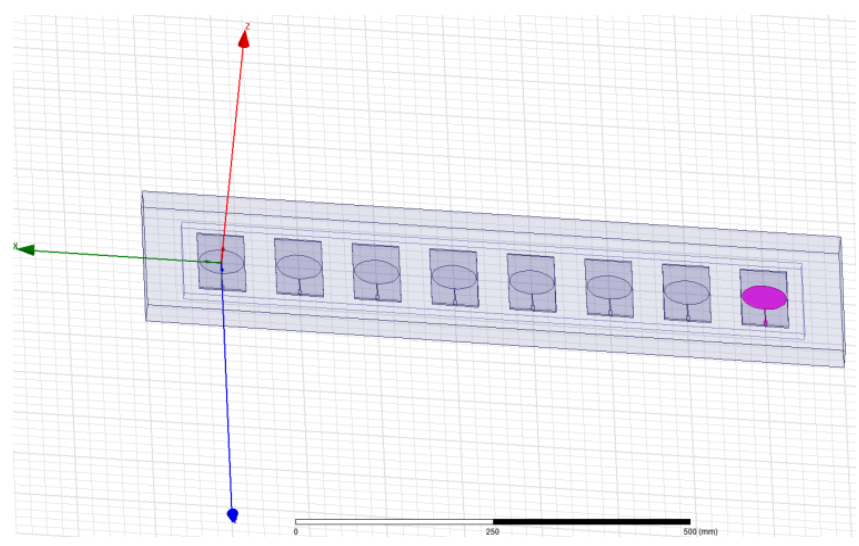

Fig.1. 8X1 circular patch phased array antenna

\section{Return Loss}

The amount of power reflected from the antenna input terminal is termed as return loss. The return loss of the proposed antenna at $2 \mathrm{GHz}$ is $-13.5682 \mathrm{~dB}$ is shown in Fig.2. The VSWR is referred as Voltage standing wave ratio, is a measure of how effectively antenna impedance is matched to the source impedance. The VSWR of the proposed antenna is 1.5307 as shown in Fig. 3. 


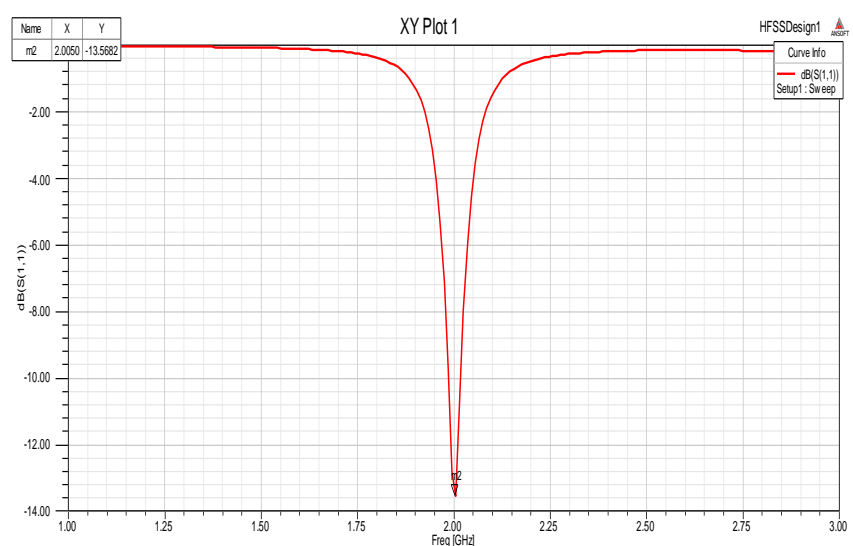

Fig.2. Return loss of the proposed antenna.

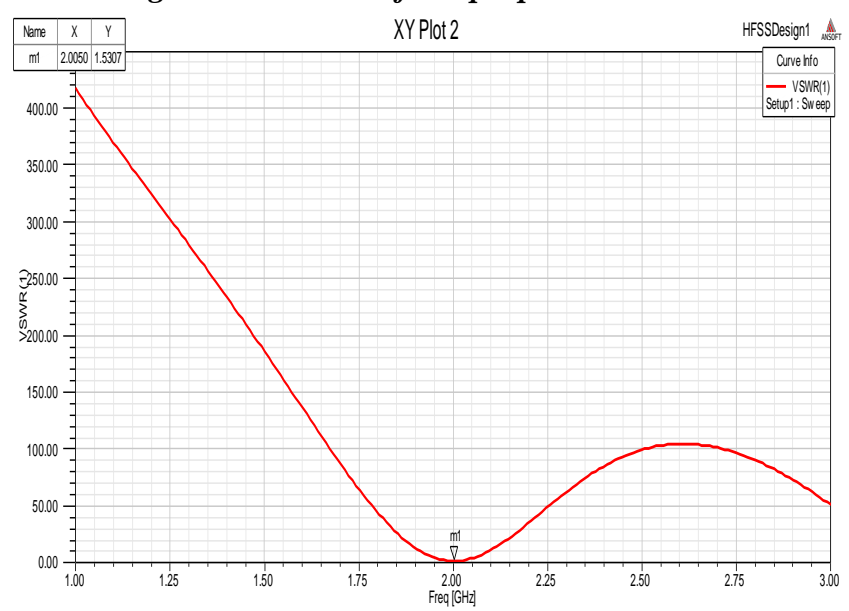

Fig.3. VSWR of the proposed antenna

Bandwidth is the range of frequencies over which antenna works satisfactorily. The Bandwidth of the proposed antenna at $2 \mathrm{GHz}$ is $57 \mathrm{MHz}$ is shown in Fig. 4.

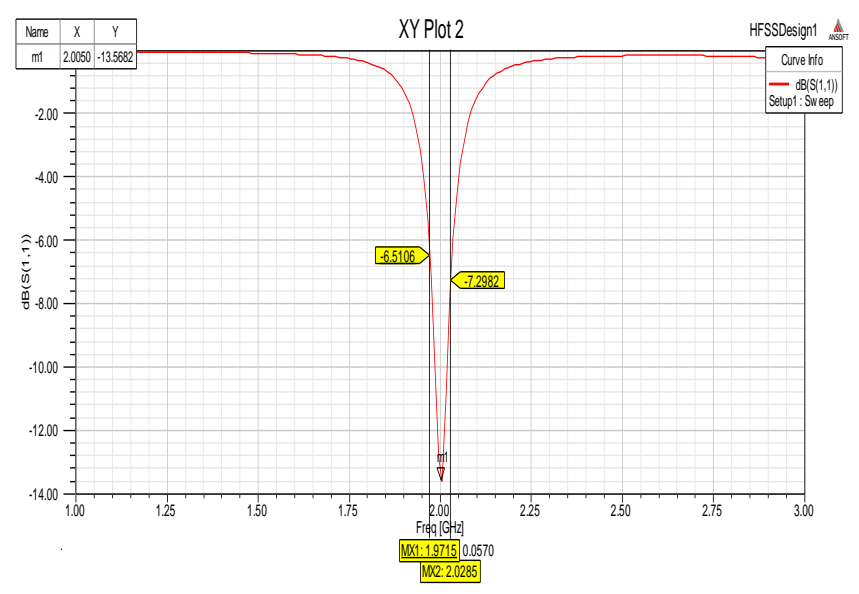

Fig 4. Bandwidth of the proposed antenna

The gain of the antenna is nothing but that is excess power transmitted by the practical antenna compared to the reference antenna that is isotropic antenna. The gain of the array antenna is $14.11 \mathrm{~dB}$ is shown in fig 5 .
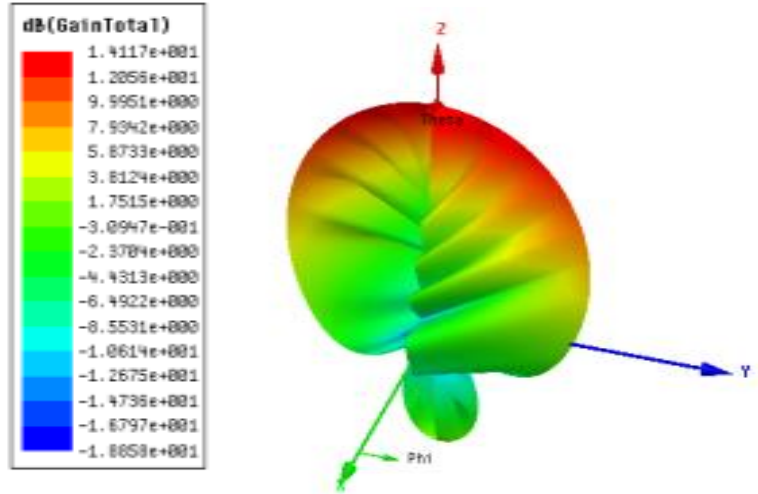

Fig 5. The gain of the array antenna.

The beam width is in general is the HPBW (Half Power Beam Width) \& it is angle separation between half power points on the main lobe. The beam widths in elevation and azimuth direction of the proposed array antennas are $13.6^{\circ}$ and $70.3^{\circ}$ is shown in Fig. 6.

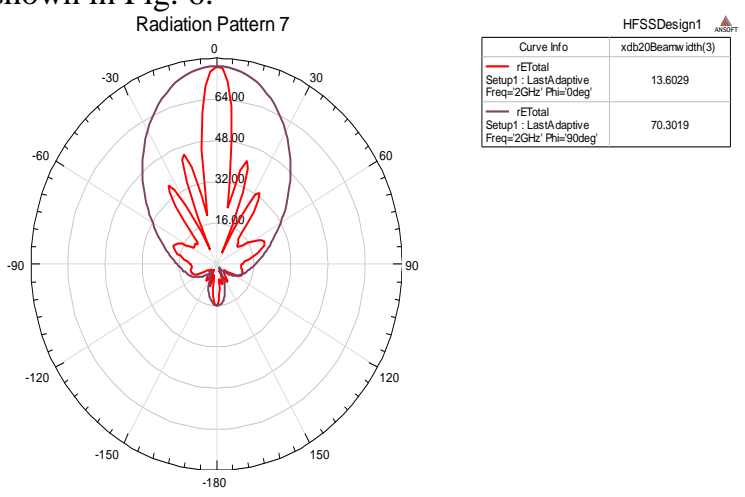

Fig.6. The beamwidths of array antenna.

The gain depends on the radiation efficiency of the antenna. The Radiation efficiency of the proposed antenna is $97.6 \%$ as shown in Fig.7.
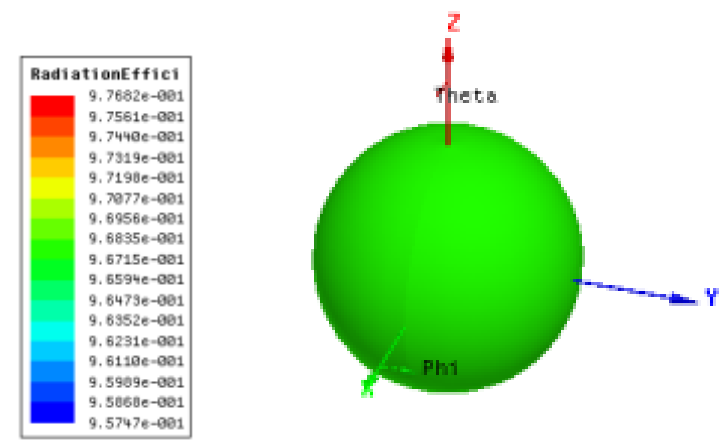

Fig. 7. Radiation efficiency of array antenna

The input impedance should match with the source impedance to minimize return loss and improve efficiency and gain. The input impedance of the proposed array antenna is shown in Fig. 8. 

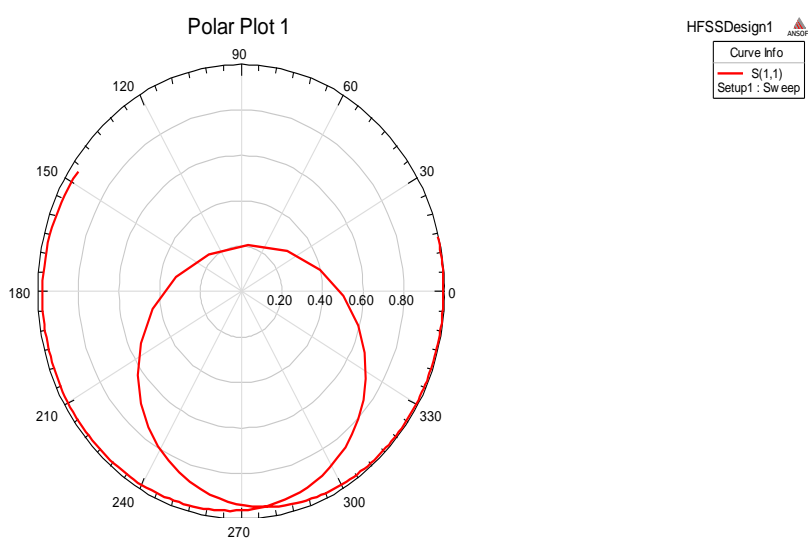

Fig . 8. Input impedance of the array antenna

III. 8X1 Circular PATCH ARRAy ANTENNA BEAM STEERING

Beam steering is nothing but changing the directions of main lobe of a radiation pattern to achieve better coverage. The direction of the main lobe can be changed simply by varying the phase difference between elements in the array.

The direction of the maximum radiation is steered in polar form at $0^{0}, 10^{0}, 20^{0}$ and $30^{\circ}$ respectively in Fig. 9(a), 9(b), 9(c), 9(d).
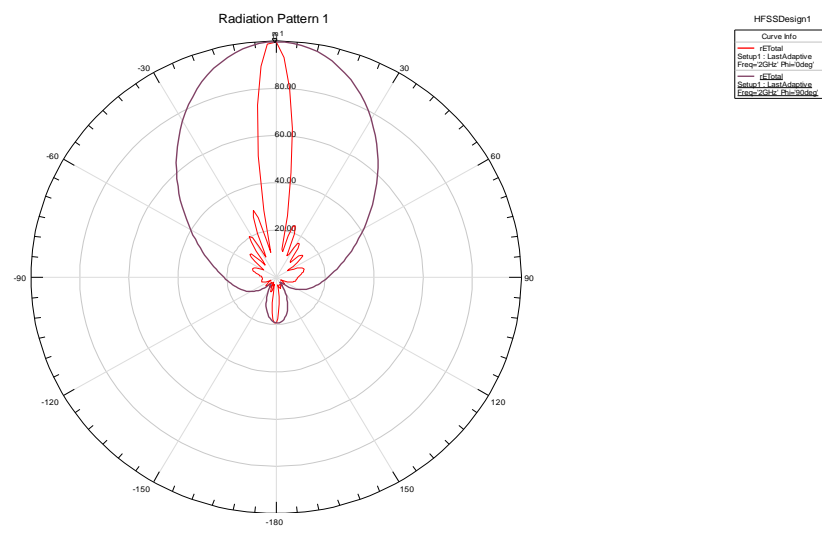

Fig.9(a). Main beam at $0^{0}$
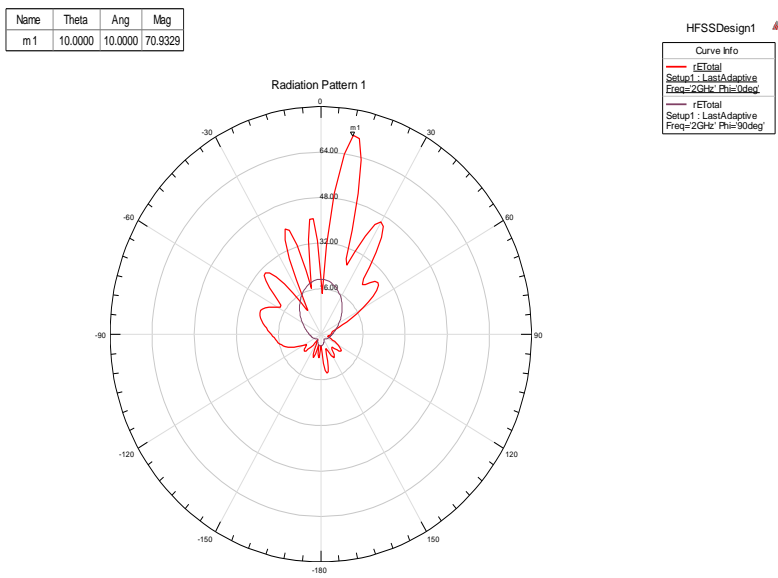

Fig.9(b). Main beam at $10^{\circ}$
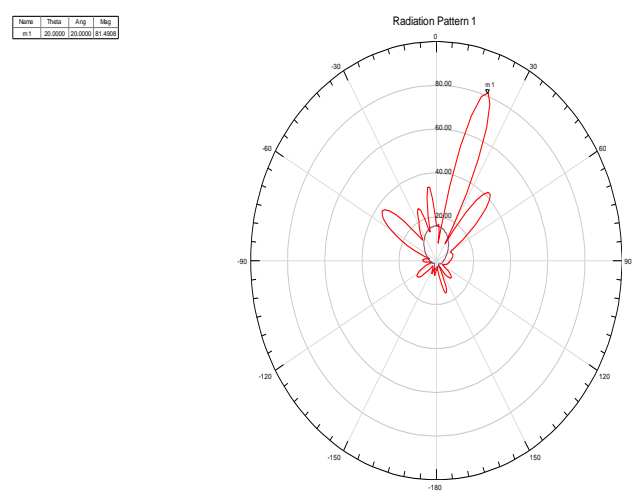

Fig.9(c). Main beam at $20^{\circ}$

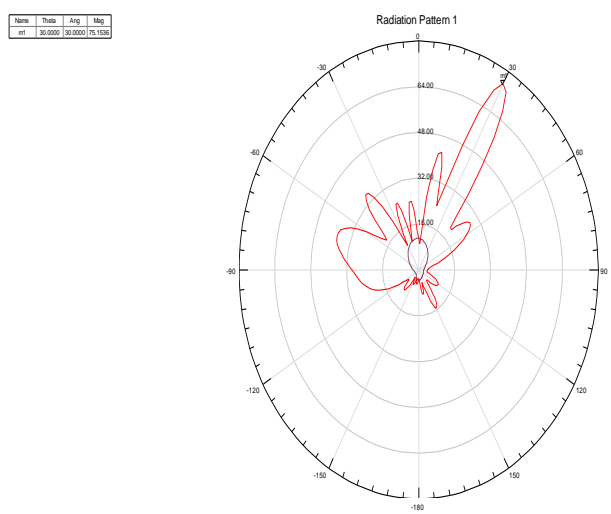

Fig.9(d). Main beam at 30

The direction of the maximum radiation is steered in rectangular form at $0^{\circ}, 10^{\circ}, 20^{\circ}$ and $30^{\circ}$ respectively in Fig. $10(\mathrm{a}), 10(\mathrm{~b}), 10(\mathrm{c}), 10(\mathrm{~d})$.

\section{$\underline{\text { Rectangular }}$}

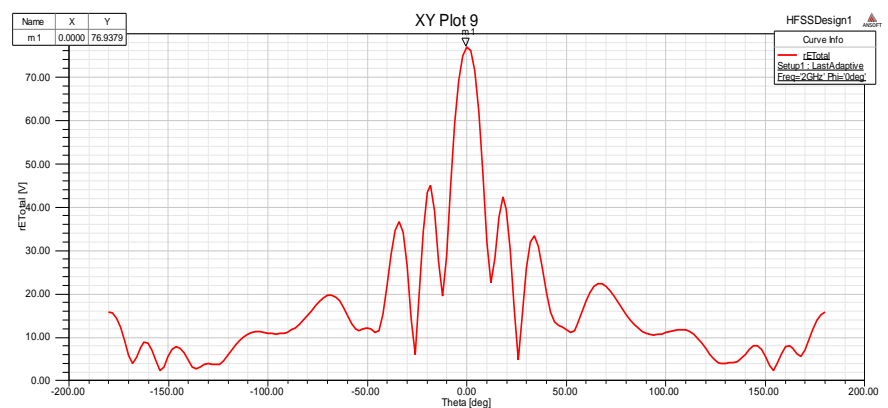

Fig.10(a). Main beam at $0^{0}$

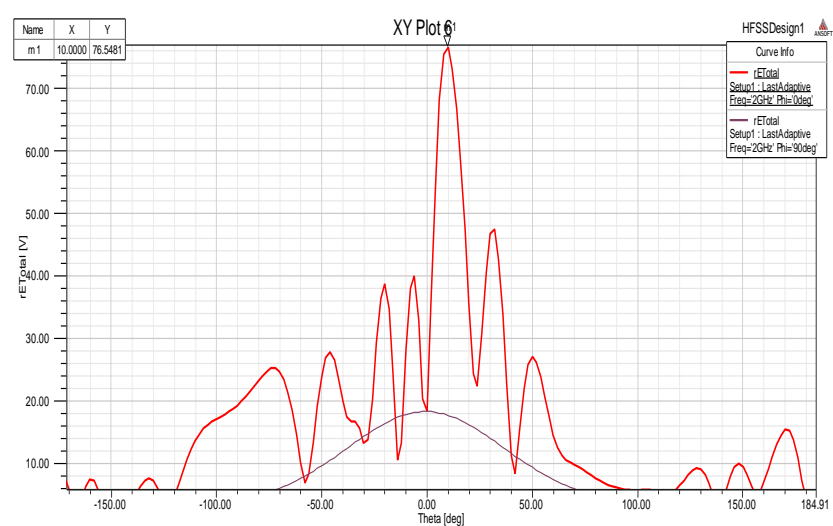

Fig.10(b). Main beam at $10^{0}$ 


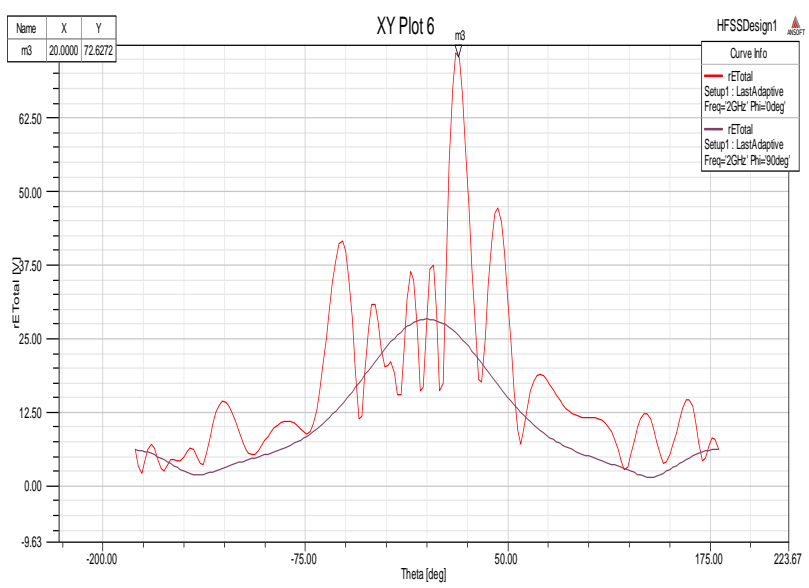

Fig.10(c). Main beam at $20^{\circ}$

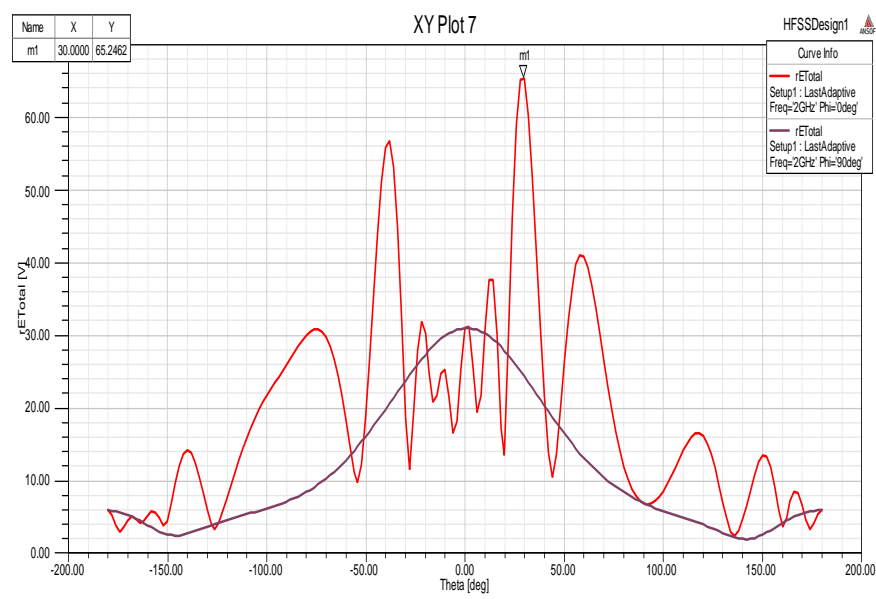

Fig.10 (d). Main beam at $30^{\circ}$

\section{DISCUSSION}

The proposed array antenna is successfully modeled and simulated using ANSOFT HFSS 15.0 and the radiation characteristics of the proposed $8 \mathrm{X} 1$ circular patch phased array antenna are summarized in the table 1 .

\section{Table 1. Radiation characteristics of the proposed antenna}

\begin{tabular}{|c|l|l|}
\hline S.No. & Parameter & \multicolumn{1}{c|}{ Value } \\
\hline 1 & Frequency & $2 \mathrm{GHz}$ \\
\hline 2 & VSWR & 1.5307 \\
\hline 3 & Return loss & $-13.5682 \mathrm{~dB}$ \\
\hline 4 & Gain & $14.11 \mathrm{~dB}$ \\
\hline 5 & E Theta & $13.6^{0}$ \\
\hline 6 & E Pi & $70.3^{0}$ \\
\hline 7 & Efficiency & $97.68 \%$ \\
\hline 8 & Bandwidth & $57 \mathrm{MHZ}$ \\
\hline
\end{tabular}

\section{CONCLUSION}

The proposed 8x1 Circular Patch Phased Array Antenna at L Band is successfully modeled and simulated. The main lobe of the array antenna beam is steered at $0^{\circ}, 10^{\circ}, 20^{\circ}$ and $30^{\circ}$ in both polar and rectangular forms. The radiation characteristics obtained by this proposed 8x1 Circular Patch Phased Array Antenna at L Band is very much useful for air borne applications.

\section{ACKNOWLEDGMENTS}

Extending our grateful thanks to the authorities of Acharya Nagarjuna University for their support and encouragement to write this paper.

\section{REFERENCES}

[1]Shen, L. C., et al., "Resonant Frequency of a Circular Disk Printed-Circuit Antenna," IEE Trans. On antennas and Propagation, Vol.AP-25, 1977, pp. 595-596.

[2]Watkins, j., "Circular Resonant structures in Microstrip," Electron. Lett. Vol. 5, 1969, pp. 524-525.

[3] Manoj Singh, Ananjan basu and S.K.Koul, " Circular Patch Antenna with Quarter wave Transformer Feed for Wireless Communications"," IEEE 1-4244-0370-7/06/\$20.00 C 2006 IEEE.

[4]Ramesh Kumar, Gian Chand, Monish Gupta, Dinesh Kumar Gupta, "Circular Patch Antenna with Enhanced Bandwidth using Narrow Rectangular Slit for Wi-Max Application,” IJECT Vol. 1, Issue 1, December 2010.

[5]Balanis, C.A., Antenna Theory Analysis and Design, John Wiley \& Sons, New York, 1997.

[6]I.J. Bhal and P. Bhartia, Microstrip antenna, Artech House, Dedgham, MA, 1980.

[7]Pozar, D.M. Microwave Engineering, John Wiley \& Sons, New York, 1998.

[8] "Antenna Engineering," in R.C. Johnson and H. Jasic (Eds.), Microstrip Antenna (2nd ed.), McGraw Hill, New York, 1984.

[9]I.J. Bhal and P. Bhartia, Microstrip antenna, Artech House, Dedgham, MA, 1980.

[10] James, J.R., P.S. Hall, and C. Wood, Microstrip antenna: Theory and design, Peter Peregrinus, London, UK, 1981.

[11] U.Srinivasa Rao, P Siddaiah, "Performance Enhancement of Microstrip Line Quarter Wave Transformer Circular Patch Antenna with Narrow Slit at L Band", International Journal of Engineering and Technical Research, ISSN: 2321-0869 (O) 2454-4698 (P), Volume-3, Issue-10, October 2015

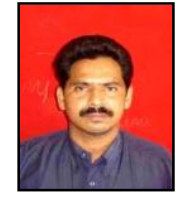

U.Srinivasa Rao obtained his B.Tech degree in Electronics and Communication Engineering from RVR\&JC College of Engineering in the year 1997. He received his M.E degree from Osmania University, Hyderabad in 2005. At present, he is pursuing his Ph.D in Acharya Nagarjuna University, Guntur, Andhra Pradesh, India. He is currently working as Associate Professor and Head, Department of ECE in Vignan's Lara institute of Technology and Science, Vadlamudi, Andhra Pradesh, India. He has taught a wide variety of courses for UG students and guided several projects. He is the life member of MISTE. His interested research areas are Microwave antennas, radar and optical communications. 